\title{
Nacre-Mimetic, Mechanically Flexible, and Electrically Conductive Silk Fibroin-MXene Composite Foams as Piezoresistive Pressure Sensors
}

Citation for published version (APA):

Bandar Abadi, M., Weissing, R., Wilhelm, M., Demidov, Y., Auer, J., Ghazanfari, S., Anasori, B., Mathur, S., \& Maleki, H. (2021). Nacre-Mimetic, Mechanically Flexible, and Electrically Conductive Silk FibroinMXene Composite Foams as Piezoresistive Pressure Sensors. ACS Applied Materials \& Interfaces, 13(29), 34996-35007. https://doi.org/10.1021/acsami.1c09675

Document status and date:

Published: 28/07/2021

DOI:

10.1021/acsami.1c09675

Document Version:

Publisher's PDF, also known as Version of record

Document license:

Taverne

Please check the document version of this publication:

- A submitted manuscript is the version of the article upon submission and before peer-review. There can be important differences between the submitted version and the official published version of record.

People interested in the research are advised to contact the author for the final version of the publication, or visit the DOI to the publisher's website.

- The final author version and the galley proof are versions of the publication after peer review.

- The final published version features the final layout of the paper including the volume, issue and page numbers.

Link to publication

\footnotetext{
General rights rights.

- You may freely distribute the URL identifying the publication in the public portal. please follow below link for the End User Agreement:

www.umlib.nl/taverne-license

Take down policy

If you believe that this document breaches copyright please contact us at:

repository@maastrichtuniversity.nl

providing details and we will investigate your claim.
}

Copyright and moral rights for the publications made accessible in the public portal are retained by the authors and/or other copyright owners and it is a condition of accessing publications that users recognise and abide by the legal requirements associated with these

- Users may download and print one copy of any publication from the public portal for the purpose of private study or research.

- You may not further distribute the material or use it for any profit-making activity or commercial gain

If the publication is distributed under the terms of Article 25fa of the Dutch Copyright Act, indicated by the "Taverne" license above, 


\section{Nacre-Mimetic, Mechanically Flexible, and Electrically Conductive Silk Fibroin-MXene Composite Foams as Piezoresistive Pressure Sensors}

Mohsen Bandar Abadi, Rene Weissing, Michael Wilhelm, Yan Demidov, Jaqueline Auer, Samaneh Ghazanfari, Babak Anasori, Sanjay Mathur, and Hajar Maleki*

Cite This: ACS Appl. Mater. Interfaces 2021, 13, 34996-35007

Read Online

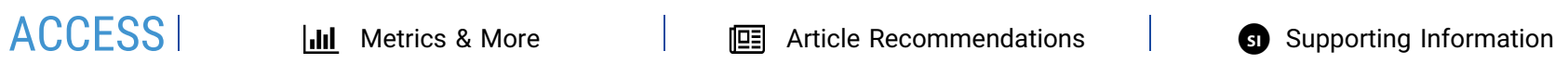

ABSTRACT: The hierarchical nacre-like three-dimensional (3D) assembly of porous and lightweight materials is in high demand for applications such as sensors, flexible energy storage and harvesting devices, electromagnetic interference shielding, and biomedical applications. However, designing such a biomimetic hierarchical architecture is highly challenging due to the lack of experimental approaches to achieve the necessary control over the materials' microstructure on the multilength scale. Aerogels and foam-based materials have recently been developed as attractive candidates for pressure-sensing applications. However, despite recent progress, the bottleneck for these materials to achieve electrical conductivity combined with high mechanical flexibility and fast strain recovery remains. In this study, for the first time, inspired by the multiscale architecture of nacre, we fabricated a series of ultralightweight, flexible, electrically conductive, and relatively high-strength composite foams through hybridizing the cross-linked silk fibroin (SF) biopolymer, extracted from

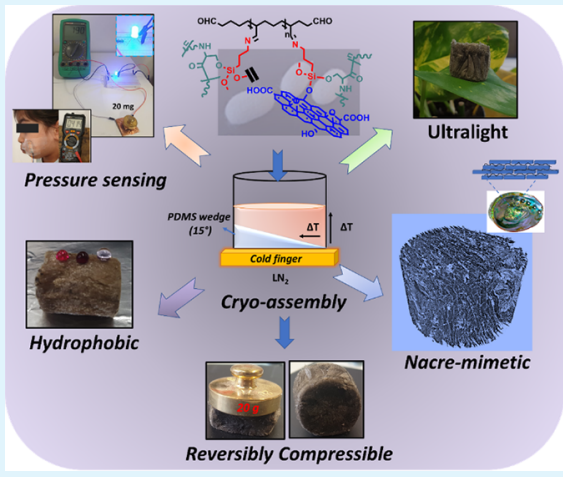
Bombyx mori silkworm cocoon, reinforced with two-dimensional graphene oxide (GO) and $\mathrm{Ti}_{3} \mathrm{C}_{2}$ MXene nanosheets. Nacre is a naturally porous material with a lightweight, mechanically robust network structure, thanks to its $3 \mathrm{D}$ interconnected lamella-bridge micromorphology. Inspired by this material, we assemble a cross-linked SF fibrous solution with MXene and GO nanosheets into nacre-like architecture using a bidirectional freeze-casting technique. Subsequent freeze-drying and gas-phase hydrophobization resulted in composite foams with 3D hierarchical porous architectures with a unique combination of mechanical resilience, electrical conductance, and ultra-lightness. The developed composite presented excellent performances as piezoresistive pressure-sensing devices and sorbents for oil/water separation, which indicated great potential in mechanically switchable electronics.

KEYWORDS: bio-inspired foams, silk fibroin, MXene, nacre, hybrid, piezoresistive wearable pressure sensor

\section{INTRODUCTION}

With the rapid development of artificial intelligence, a new set of materials for smart sensing and biomimetic robot technology are highly demanded. ${ }^{1}$ A pressure sensor system, which can transduce strain and its variation into resistance, electrical potential, and capacitor, recently attracted significant attention for the development of wearable functional electronics. ${ }^{2}$ Piezoresistive sensors transduce pressure stimuli into the changes in the resistance. The combination of mechanical compliance, i.e., high flexibility and fast strain relaxation after deformation, and appropriate electrical performance is crucial for creating highly sensitive flexible pressure sensors. ${ }^{2,3}$

Recently, controlled assembly of porous macrostructures using renewable resources and functional nanofillers with a large specific surface area and outstanding mechanical, electrical, or thermal properties has drawn significant attention for some applications, including flexible devices, ${ }^{4,5}$ catalysts, ${ }^{6}$ sensors, ${ }^{7}$ energy storage, ${ }^{8}$ and electromagnetic interference shielding materials. ${ }^{9,10}$ In this regard, lightweight foams based on sustainable precursors with cellular microarchitecture have demonstrated enormous potential for processing advanced structural and functional materials. ${ }^{11}$

Our previous studies have shown the potential of novel silk fibroin (SF)-based aerogels, denoted AeroSF, ${ }^{12}$ and their composite counterparts ${ }^{13,14}$ for diverse advanced applications, such as thermal insulation, water/oil separation, and as scaffolds for bone repair. ${ }^{15,16} \mathrm{SF}$, a biopolymer extracted from Bombyx mori silkworm cocoon, is a biocompatible and biodegradable fibrous protein. Thanks to its promising features such as processability, abundant surface functional groups, and

Received: May 25, 2021

Accepted: June 28, 2021

Published: July 14, 2021 


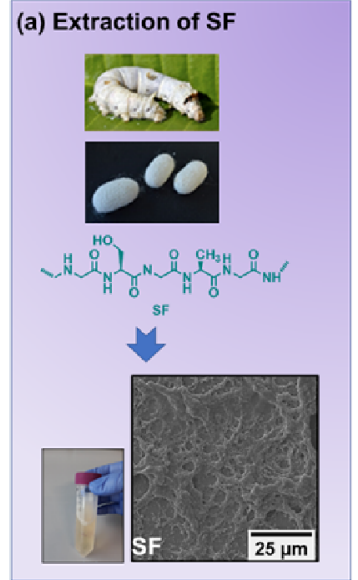

(d) Surface modifications 8 cross-linking of SF

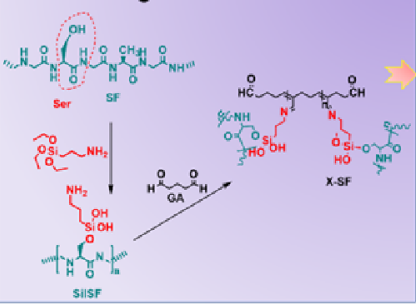

(f) Cryo-assembly and freeze drying
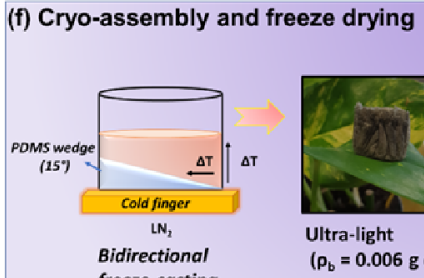

freeze-casting
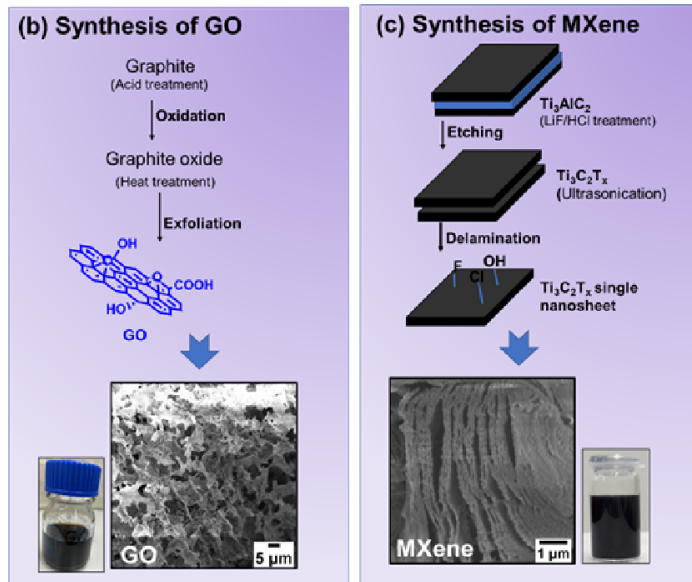

(e) SF hybridization with 2D nanosheets of MXene \&

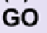

O

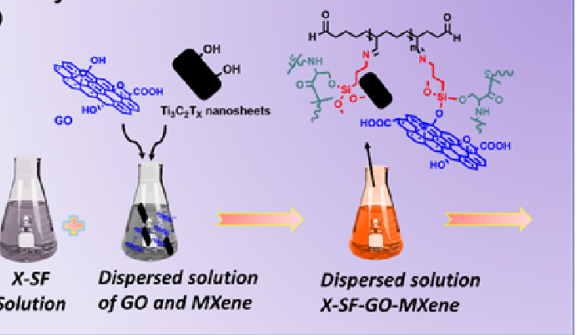

(g) Gas phase hydrophobization with HMDS

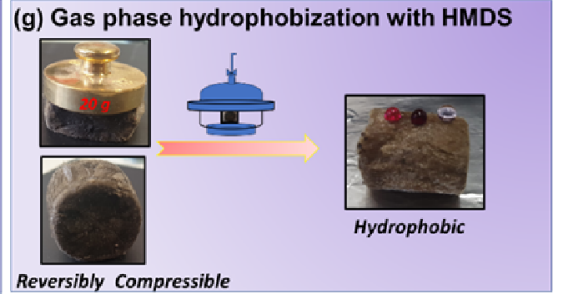

Figure 1. Fabrication procedure of nacre-mimetic X-SF-MXene-GO hybrid foams through a bidirectional freeze-casting approach and gas-phase hydrophobization. (a) Extraction process of SF and the SEM micrograph, which indicates the fibrous nature of pristine-extracted SF. (b) Synthesis process of GO (foam) and (c) MXene nanosheets with their SEM micrographs prior to engaging them in the hybridization process and 3D cryoassembly. (d) The surface modification of extracted SF with APTES and subsequent cross-linking with GA. (e) Incorporation of nanosheets into the X-SF solution to obtain a highly dispersed solution of X-SF-MXene-GO. (f) Bidirectional freeze-casting of the stable solution of X-SF-MXeneGO, freeze-drying of the obtained frozen samples, and a piece of ultralight X-SF-MXene9-GO foam that can easily sit on the leaf. (g) Gas-phase hydrophobization of the composite X-SF-MXene9-GO foams.

mechanical strength, it has been recently used to develop various functional (bio)materials. ${ }^{17}$ However, the SF aerogel by itself is not able to show enough elasticity or fast elastic deformation upon compression or deformation. Additionally, it is electrically nonconductive. Thus, for applications such as pressure sensing, it is required to improve the SF aerogel mechanical resilience and electrical conductivity by the incorporation of active components to add both properties to the composite. Our previous studies have demonstrated that hybridization of SF with various organosilanes at a molecular scale through self-assembly of SF peptides inside the sol-gelprocessed silica $^{12,14}$ and silsesquioxane gel $^{13}$ network could improve the compression flexibility of pristine silica and could provide a high compression/bending strength to the pristine silsesquioxane aerogels.

In this study, we incorporated $\mathrm{Ti}_{3} \mathrm{C}_{2} \mathrm{~T}_{\mathrm{x}}$ MXene and graphene oxide (GO) nanosheets into the SF network as functional nanoadditives to solve its conductivity and elasticity limitations. With their excellent physicochemical and mechanical properties, GO and reduced $\mathrm{GO}^{18,19}$ have shown great potential as functional nanoadditives for polymeric architec- tures and aerogels, endowing them with high mechanical resilience and electrical conductivity. ${ }^{20,21}$ MXene nanosheets, ${ }^{22,23}$ recently emerged two-dimensional (2D) transition metal carbides (in this study, titanium carbide, $\mathrm{Ti}_{3} \mathrm{C}_{2} \mathrm{~T}_{x}, \mathrm{~T}_{x}$ : $\mathrm{OH},-\mathrm{F}$, and $=\mathrm{O}$ ), have also shown many impressive material properties, including large specific surface area, high electrical conductivity (up to $20000 \mathrm{~S} \mathrm{~cm}^{-1}$ ), ${ }^{24}$ and high mechanical stiffness $(330 \pm 30 \mathrm{GPa})^{25,26}$ for various advanced applications. $^{27}$ MXene composite aerogels combined with cellulose and GO have been previously reported by $\mathrm{Bi}$ et al. ${ }^{28}$ and $\mathrm{Ma}$ et al. ${ }^{29}$ for wearable pressure-sensing applications. However, there are no systematic studies to combine the intriguing biocompatibility and processability of SF with electrical conductivity of MXene nanosheets to develop three-dimensional (3D) synergistic foams.

Despite the impressive development of optimized building units with porous architectures in pressure sensing, most of the structures reported so far possess isotropic or randomly oriented cross-linked cellular networks due to the difficulty in controlling the pore shape and morphology. ${ }^{30,31}$ Recently, we developed anisotropic silica-SF biopolymer aerogels ${ }^{15,16}$ with a 
Table 1. Different Formulations of X-SF-MXeneY-GO Composite Foams Prepared in this Study with Their Bulk Density Values

\begin{tabular}{lccccc}
\multicolumn{1}{c}{ samples } & X-SF $(\mathrm{mg})$ & MXene $(\mathrm{mg})$ & GO $(\mathrm{mg})$ & {$[\mathrm{MXene}] /[\mathrm{X}-\mathrm{SF}]$} & bulk density $\left(\rho_{\mathrm{b}}, \mathrm{g} \mathrm{cm}^{-3}\right)$ \\
X-SF-MXene0.01-GO & 25 & 0.3 & 1 & 0.01 & 0.066 \\
X-SF-MXene0.05-GO & 6 & 0.3 & 1 & 0.05 & 0.025 \\
X-SF-MXene0.33-GO & 6 & 2 & 1 & 0.33 & 0.029 \\
X-SF-MXene9-GO & 1 & 9 & 1 & 9 & 0.01 \\
X-SF-MXene5-GO & 1 & 5 & 1 & 5 & 0.006
\end{tabular}

microhoneycomb-like microstructure and anisotropic mechanical behavior through unidirectional freeze-casting of the asprepared silica-SF hydrogels followed by the supercritical drying approach. In this regard, we demonstrated that by carefully controlling the microstructure and pore morphology with freeze-casting parameters, the aerogels' final mechanical properties could be significantly controlled (maximum compression strength $\sim 20 \mathrm{MPa}$ with elasticity up to $80 \%$ of the strain). ${ }^{16}$

In the present study, ultralight and compressible multicomponent foam-based pressure sensors with biomimetic microstructures were fabricated through compositing glutaraldehyde (GA)-cross-linked SF (called X-SF hereafter), GO, and $\mathrm{Ti}_{3} \mathrm{C}_{2} \mathrm{~T}_{x}$ MXene, followed by processing the obtained hybrid sol through a versatile and well-studied bioinspired processing approach of bidirectional freeze-casting. In bidirectional freeze-casting, lamellar ice crystals are used to assemble ceramics, polymers, and composite particles/building blocks into a highly aligned biomimetic $3 \mathrm{D}$ porous network structure. $^{32-36}$

Since nacre has a hierarchical microarchitecture with an excellent combination of strength and toughness, it served as a source of inspiration in this study for foam microstructuration and network formation using the bidirectional freeze-casting approach. $^{37,38}$ The developed dispersion has undergone the thermal gradient in two different directions, allowing the cryoassembling of the network constituents into nacre-mimetic "brick-and-mortar" or lamella-bridge micromorphologies. It is demonstrated that the synergistic combination of SF with MXene and GO nanosheets endows the sensor with desirable ultralow density, high electrical conductivity, reversible compressibility, and durable stability. While stable and homogeneous dispersion of the MXene nanosheet in the XSF matrix makes it electrically conductive, incorporation of GO into the matrix endows the overall final composite foams with extra compressibility and resilience.

Final gas-phase hydrophobization of the pore surface confers an extra feature of oleophilicity and hydrophobicity to the final composite foams. To the best of our knowledge, there is no report on the synergistic 3D assembly of SF biopolymers with MXene and GO to prepare composite foams that combine both high elasticity and hydrophobicity properties. The fabricated foam can act as a highly sensitive pressure sensor and sorbent for the separation of oils and organic solvents from water.

\section{EXPERIMENTAL SECTION}

B. mori cocoons were purchased from Treenway Silks, USA. Aminopropyltriethoxysilane (APTES, 99\%), ethanol (99.9\%, $\mathrm{EtOH})$, calcium chloride $\left(99.99 \%, \mathrm{CaCl}_{2}\right)$, sodium carbonate $\left(\mathrm{Na}_{2} \mathrm{CO}_{3}\right)$, and $\mathrm{GA}(50 \%$ in water) were purchased from Sigma Aldrich. SnakeSkin dialysis tubing with a molecular weight cutoff of $3.5 \mathrm{kDa}$ was purchased from Thermo Fisher Scientific. Titanium aluminum carbide powder $\left(\mathrm{Ti}_{3} \mathrm{AlC}_{2}, 99 \%\right)$ was purchased from
Nanoshel. Lithium fluoride ( $\mathrm{LiF}, 98 \%)$ was purchased from Alfa Aesar.

2.1. SF Extraction. SF was extracted from B. mori silkworm cocoons by a modified procedure based on the protocols of Rockwood et al. ${ }^{17}$ and Zheng et al. ${ }^{39}$ First, worm-free B. mori cocoons $(5 \mathrm{~g})$ were cut into dime-size pieces and boiled in an aqueous sodium carbonate solution $(0.02 \mathrm{~m}, 2 \mathrm{~L})$ for $30 \mathrm{~min}$ to remove sericin. The dried and degummed SF fibers $(4 \mathrm{~g})$ were dissolved in $20 \mathrm{~mL}$ of Ajisawa's reagent (calcium chloride/ethanol/water: 1:2:8 (molar ratio)) at $80^{\circ} \mathrm{C}$ for $3 \mathrm{~h}$ and dialyzed against distilled water for $48 \mathrm{~h}$ in dialysis bags $(9 \mathrm{~cm})$ while changing the water every $3 \mathrm{~h}$. After removing worm debris and globular silk aggregates via centrifugation $(2 \times 9000 \mathrm{rpm})$, concentrated SF solution $\left(0.04 \mathrm{~g} \mathrm{~mL}^{-1}\right)$ was stored at $4{ }^{\circ} \mathrm{C}$ for future use (Figure 1a).

2.2. Synthesis of GO. GO was prepared based on improved Hummers' method. ${ }^{40,41}$ A 9:1 mixture of concentrated $\mathrm{H}_{2} \mathrm{SO}_{4} / \mathrm{H}_{3} \mathrm{PO}_{4}$ $(360: 40 \mathrm{~mL})$ was added to a mixture of graphite flakes $(3.0 \mathrm{~g})$ and $\mathrm{KMnO}_{4}(18.0 \mathrm{~g})$. The resulting mixture was heated to $50{ }^{\circ} \mathrm{C}$ and stirred for $12 \mathrm{~h}$. After cooling to ambient temperature, the reaction mixture was poured on ice $(400 \mathrm{~mL})$ with $30 \% \mathrm{H}_{2} \mathrm{O}_{2}$. The brownish mixture was centrifugated $(4500 \mathrm{rpm}, 15 \mathrm{~min})$ and washed with water, $30 \% \mathrm{HCl}$, and ethanol (Figure $1 \mathrm{~b}$ ). After filtration, the obtained solid was dried in a vacuum oven at ambient temperature. The concentration of GO solution was quantified by drying and weighing the GO film.

2.3. Synthesis of $\mathrm{Ti}_{3} \mathrm{C}_{2} \mathrm{~T}_{\boldsymbol{x}}$ MXene. $\mathrm{Ti}_{3} \mathrm{C}_{2} \mathrm{~T}_{x}$ MXene $2 \mathrm{D}$ nanosheets were synthesized by the selective etching method from its $\mathrm{Ti}_{3} \mathrm{AlC}_{2}$ precursor, which is reported elsewhere. ${ }^{42}$ Lithium fluoride powder (1 g) (LiF, Alfa Aesar, 98+\%) was slowly added into $20 \mathrm{~mL}$ of $9 \mathrm{M}$ hydrochloric acid ( $\mathrm{HCl}$, Fisher, technical grade, 35-38\%) and stirred for $30 \mathrm{~min}$. Then, MAX phase $\mathrm{Ti}_{3} \mathrm{AlC}_{2}$ powder $(1 \mathrm{~g})$ was slowly added into the mixture solution to etch the $\mathrm{Al}$ layer at $35{ }^{\circ} \mathrm{C}$ for $24 \mathrm{~h}$. The acidic supernatant was removed by a repeated centrifugation process at $9000 \mathrm{rpm}$ (approximately 8-10 times) to finally obtain a stable dark green supernatant of $\mathrm{Ti}_{3} \mathrm{C}_{2} \mathrm{~T}_{x}$ with a $\mathrm{pH}$ of $\sim 6$ (Figure 1c). The concentration of $\mathrm{Ti}_{3} \mathrm{C}_{2} \mathrm{~T}_{x}$ MXene solution was quantified by drying and weighing the MXene film. We will refer to $\mathrm{Ti}_{3} \mathrm{C}_{2} \mathrm{~T}_{x}$ MXene as MXene in the rest of this study for the sake of simplicity.

2.4. Cross-Linking of SF with GA (X-SF). First, the extracted SF $(4 \mathrm{~mL}, 40 \mathrm{mg} / \mathrm{mL})$ solution was modified with APTES to prepare silylated SF (SilSF) with amino functionalities through the addition of APTES $(0.12 \mathrm{~mL}, 0.51 \mathrm{mmol})$ at room temperature for $30 \mathrm{~min}$. Then, the obtained SilSF solution was dialyzed against distilled water to wash the unreacted APTES from the SilSF solution for $2 \mathrm{~h}$ at room temperature. Next, $4 \mathrm{~mL}$ of purified SilSF solution was added to the reaction with a GA cross-linker $(25 \mathrm{v} / \mathrm{v} \%, 6.12 \mathrm{mmol}, 0.24 \mathrm{~mL})$. The color of the solution turned dark orange in 2 min (Figure 1d).

2.5. Propylene Mold with a PDMS Wedge. According to Yang et al., ${ }^{38} 1 \mathrm{~mL}$ of polydimethylsiloxane (PDMS) solution (Sylgard 184, Dow Corning) was added into a cylindrical propylene mold $(1 \mathrm{~cm})$, and the mold was tilted to an angle of $20^{\circ}$. After curing in an oven at $80{ }^{\circ} \mathrm{C}$ for $2 \mathrm{~h}$, the PDMS wedge was obtained.

2.6. Synthesis of X-SF-MXeneY-GO. First, $2 \mathrm{~mL}$ of mixed colloidal solution of $\mathrm{GO}(1.2 \mathrm{mg} / \mathrm{mL})-$ MXene with varying concentrations of MXene was ultrasonicated for $1 \mathrm{~h}$ under argon (Ar) and then was added to $4.24 \mathrm{~mL}$ of the above-mentioned X-SF solution with varying concentrations shown in Table 1 . The $\mathbf{Y}$ values defined as the MXene/X-SF mass ratio were adjusted to 0.01, 0.05, 

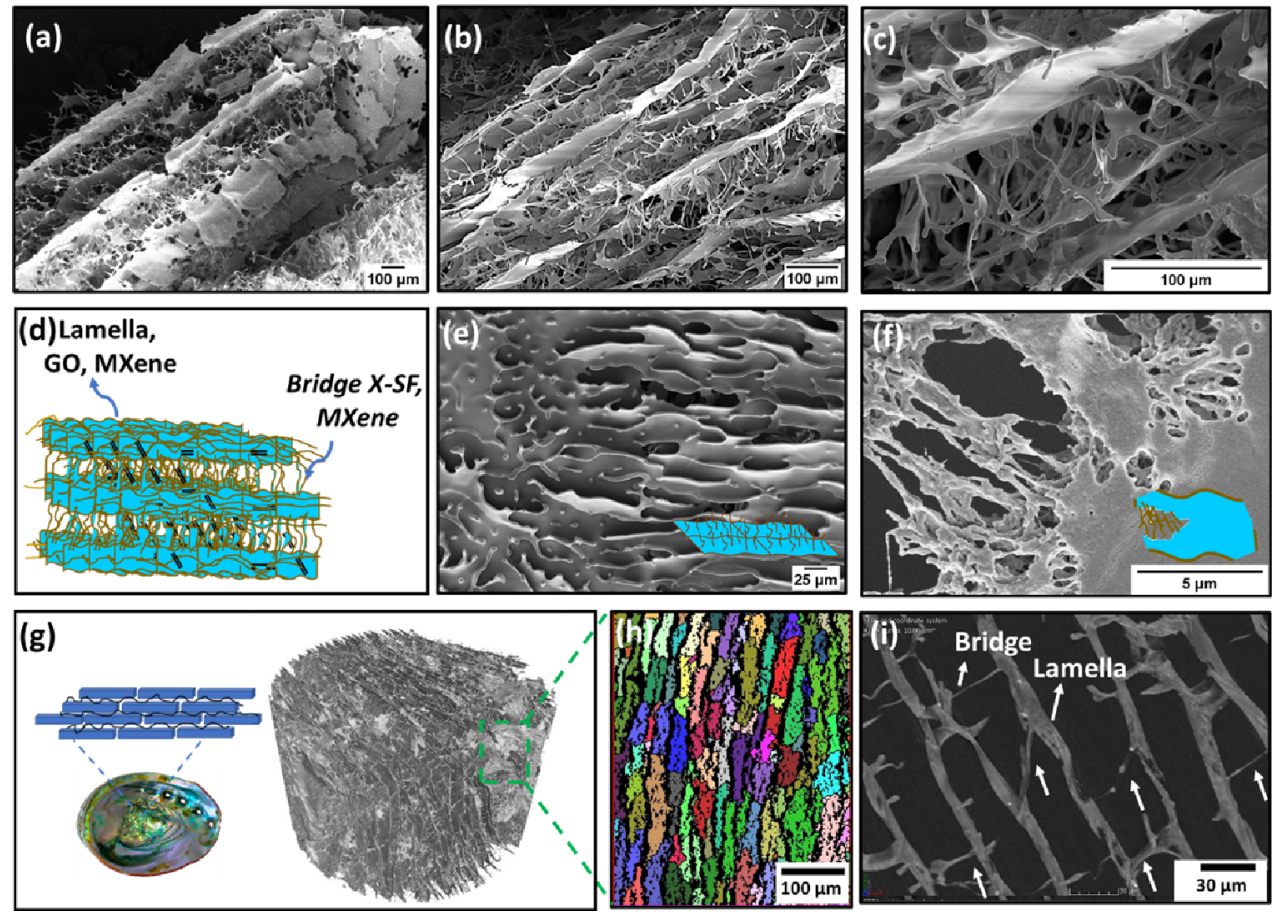

Figure 2. $(\mathrm{a}-\mathrm{c})$ Multiscale SEM micrographs of the porous microstructures of X-SF-MXene9-GO; (d) the proposed schematic view from the bridges and lamellae in the composites; (e and $\mathrm{f}$ ) the hierarchical structure of the lamellae with an intertwined structure of all network building blocks; (g) microstructural scheme of nacre and 3D reconstructions of the porous structure of X-SF-MXene9-GO derived from X-ray microcomputed tomography, which shows the alignment of the porous structure along the ice growth direction (image of abalone in lower left reprinted with permission from ref 46 . Copyright 2021 Academic Press/Elsevier); ${ }^{46}$ and (h) and (i) X-ray nanotomography images showing the nacre-mimetic bridge and lamella microstructural morphology.

$0.33,5$, and 9 . After $5 \mathrm{~min}$ of stirring at room temperature, the stable mixed colloidal solution was transferred into the sample containers covered with the PDMS wedge, sealed, and then brought into contact with a cold copper block immersed in a liquid nitrogen $\left(\mathrm{LN}_{2}\right)$ bath for bidirectional freeze-casting of the mixed solution by applying a dual temperature gradient to the solution. The samples were finally freezedried at $60^{\circ} \mathrm{C}$ for $24 \mathrm{~h}$ (Figure le,f).

2.7. Gas-Phase Hydrophobization of X-SF-MXeneY-GO Composite Foams. The dried monoliths were modified with methyl groups on the surface by placing the cylindrical porous foams with dimensions of $1.5 \times 1 \mathrm{~cm}^{2}$ inside the desiccator that was filled with hexamethyldisilazane (HMDS, $10 \mathrm{~mL}$ ) under an argon atmosphere and heated for $70{ }^{\circ} \mathrm{C}$ for $24 \mathrm{~h}^{43,44}$ Afterward, the desiccator was degassed, and the treated porous network surface was monitored by measuring the water contact angle (WCA) (Figure 1g).

\section{RESULTS AND DISCUSSION}

Figure $1 \mathrm{a}-\mathrm{g}$ illustrates the fabrication route for X-SF-MXeneGO hybrid composite foams. First, SF had undergone crosslinking with GA (the product is called cross-linked SF or X-SF) through prior surface modification with APTES to enhance the surface amino groups for cross-linking.

An aqueous suspension of highly dispersed X-SF, MXene, and GO was frozen by a bidirectional freezing technique (Figure 1f). Upon freezing, the thermally insulating PDMS wedge (placed between the suspension and the cooling stage) generated dual temperature gradients in both vertical $\left(\Delta T_{\mathrm{V}}\right)$ and horizontal $\left(\Delta T_{\mathrm{H}}\right)$ directions. ${ }^{32}$ The temperature gradient in both directions governed the ice crystal nucleation and growth inside the mixture slurries into a long-range lamellar pattern. $^{34}$ In the bidirectional freezing technique, the ice lamella acts as a hard template for the final structures of biomimetic X-SF-MXene-GO foams after sublimation. The ice crystal nucleation and growth pattern and subsequent final microarchitectures, such as porosity and anisotropy, were tuned by parameters such as suspension concentration/ viscosity, the slope angle of the PDMS wedge, and the cooling rate. ${ }^{33,38,45}$ The bidirectional freezing technique is known as a simple, generic, and green (in the majority) method to fabricate highly ordered cellular materials with different constituents, namely, ceramics, polymers, and their composites. $^{34}$ The technique has also been frequently used for generating the bridge-and-lamella or brick-and-mortar nacremimetic structures from ceramic/carbon and polymer slurries. $^{34-36}$

MXene with a layered "clay" structure (cf. scanning electron microscopy (SEM) image in Figure 1c) was produced by an established method reported by Gogotsi et al. ${ }^{2,23}$ through selective etching of the $\mathrm{Al}$ layer from the $\mathrm{MAX}\left(\mathrm{Ti}_{3} \mathrm{AlC}_{2}\right)$ phase. The combination of high electrical conductivity and electrophilic nature of the hydroxyl- and oxygen-terminated surface in MXene enables it to become an exciting nanofiller candidate for SF-based composite foams of this study.

During freezing, MXene, GO, and X-SF were expelled and assembled to replicate the ice micromorphology. Finally, the XSF-MXene-GO composite was obtained by freeze-drying the frozen samples. Due to the presence of abundant available $-\mathrm{OH}$ surface groups, composites were subjected to surface treatment in the gas phase by HMDS to functionalize the methyl groups to increase the surface hydrophobicity.

3.1. Physical, Microstructural, and Mechanical Properties. As shown in Table 1 , we fabricated a series of composites with mass fractions of MXene to X-SF of 0.01, $0.05,0.33,5$, and 9. We used different mass fractions to identify an optimum ratio to achieve a balance of the 

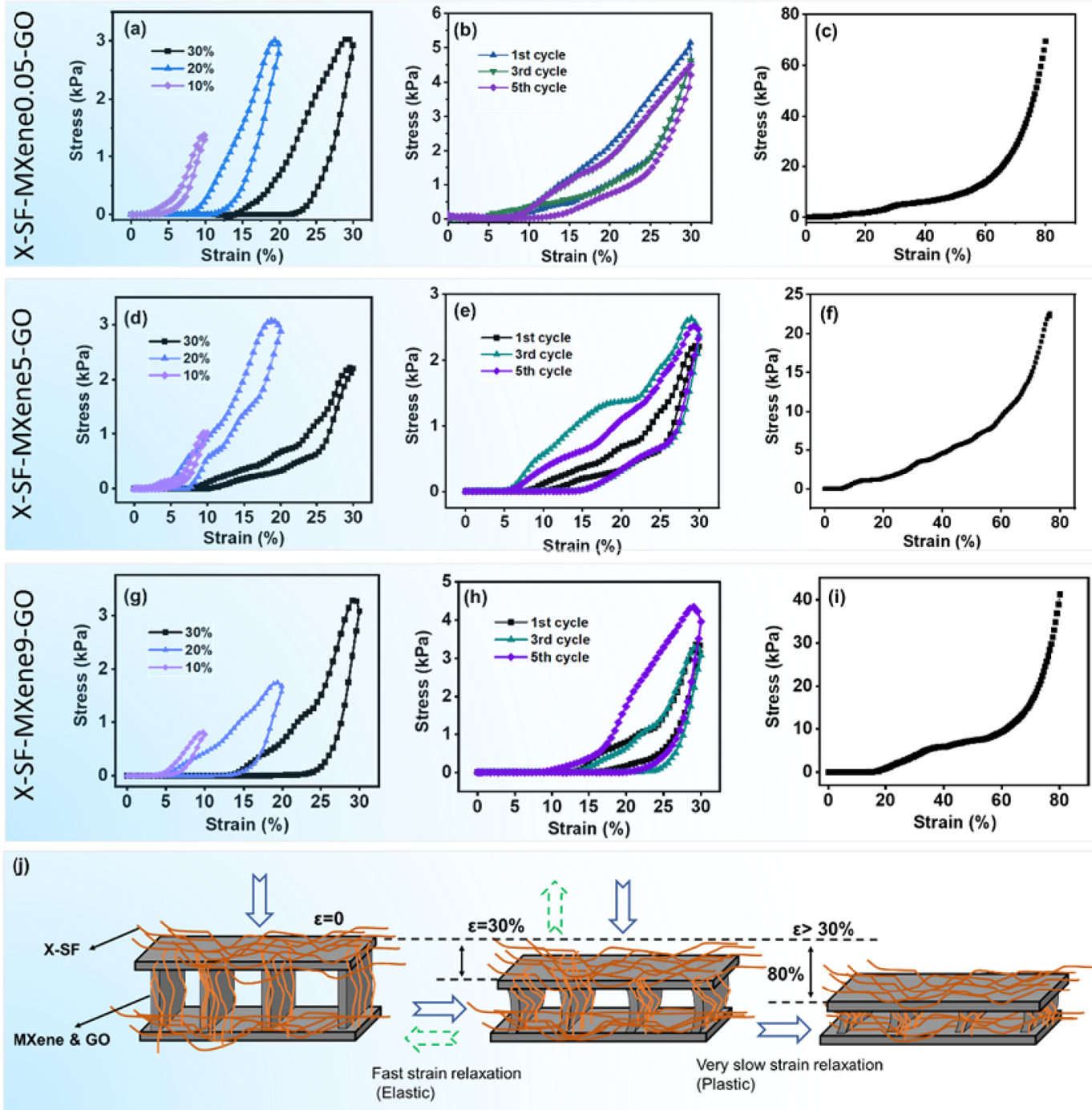

Figure 3. Compressive behavior of the X-SF-MXene0.05-GO sample under the cyclic compression test with an increasing strain of $10 \%$, $20 \%$, and $30 \%$ (a), five repeated cycles at $30 \%$ (b), and the stress-strain curve until sample's failure (c). Compressive behavior of the X-SF-MXene5-GO samples under the cyclic compression test with an increasing strain of $10 \%, 20 \%$, and $30 \%$ (d), five repeated cycles at $30 \%$ (e), and the representative stress-strain curve until sample's failure (f). Compressive behavior of the X-SF-MXene9-GO samples under the cyclic compression test for an increasing strain of $10 \%, 20 \%$, and $30 \%(\mathrm{~g})$, five repeated cycles at $30 \%(\mathrm{~h})$, and stress-strain curve until sample's failure (i). Strain relaxation of X-SF-MXene0.05, 5, and 9-GO samples up to $\varepsilon=30 \%$ and slow relaxation to plastic deformation at $\varepsilon>30 \%$ (j).

mechanical and electrical behavior in the final composites. The densities of the composites were measured in a very low range of $\rho_{\mathrm{b}}=0.006-0.066 \mathrm{~g} \mathrm{~cm}^{-3}$. The highest density was measured for the composite with the maximum SF and MXene contents. The lowest bulk density was obtained for the sample X-SFMXene5-GO $\left(0.006 \mathrm{~g} \mathrm{~cm}^{-3}\right)$, which is considerably lower than that of the previously developed SF-based aerogel composite of $\sim 0.1 \mathrm{~g} \mathrm{~cm}^{-3}$. $^{14}$

The SEM images in Figure 2a-c demonstrate the long-range and hierarchically aligned nacre-mimetic brick-and-mortar or lamella-bridge network structures. In such nacre-mimetic structures, GO and MXene 2D nanosheet building blocks were well-dispersed and intertwined together with the crosslinked SF biopolymer and constituted the bridge structures (Figure $2 \mathrm{~d}-\mathrm{f}$ ). Additionally, a part of X-SF is located as a spring or mortar between the bricks or lamellae in the composite structure (Figure 2c), which increases the network stability and resilience. The brick-and-mortar microstructural arrangement of the sample was also evident from the micro-
nano-CT analysis, as shown in Figure $2 \mathrm{~g}-\mathrm{i}$. The recorded nano-CT in Figure $2 \mathrm{i}$ reveals that the anisotropic pore channel alignment was in the parallel direction to the ice crystal growth and created cross-bridges between the lamellae at lower length scales.

We then measured the elastic modulus, cyclic stress-strain, and failure strength under compression for three sets of compositions, X-SF-MXene0.05-GO, X-SF-MXene5-GO, and X-SF-MXene9-GO (Figure 3). While pristine $\mathrm{SF}^{12}$ and MXene $^{29}$ foams/aerogels without additives deformed at relatively lower strain (10\%), X-SF-MXene-GO composite foams, thanks to their unique microstructural assembly, could be compressed under cyclic compression and decompression at $10 \%, 20 \%$, and $30 \%$ of strains $(\varepsilon)$ without collapsing or failure (cf. Figure 3a,d,g). The elastic modulus $(E)$ was measured from the most linear part of the first compression cycle of the stress-strain curves for all samples. The $E$ values of the composites were measured to be $0.052 \mathrm{kPa}$ (X-SFMXene9-GO), $0.11 \mathrm{kPa}$ (X-SF-MXene0.05-GO), and 0.047 
(a)
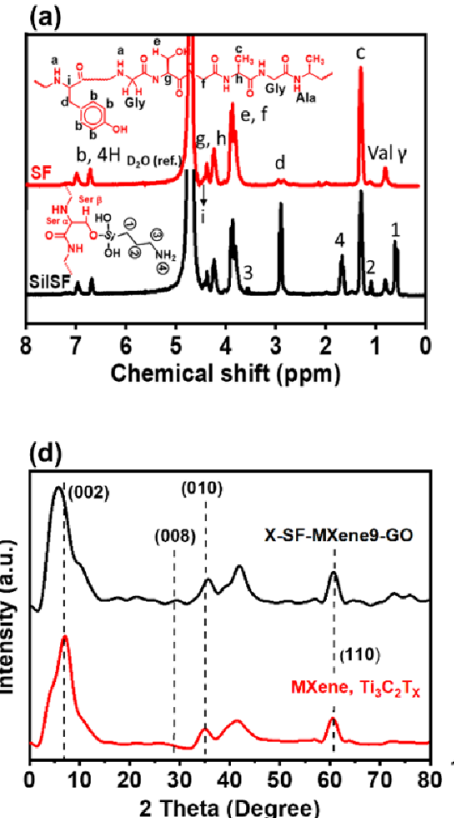

(b)
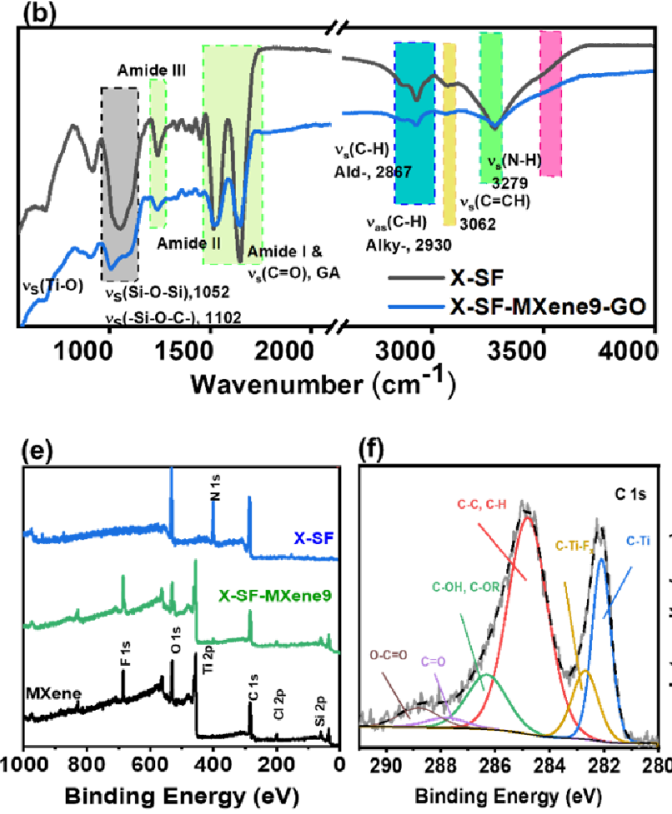

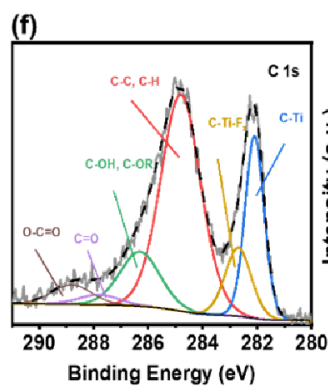

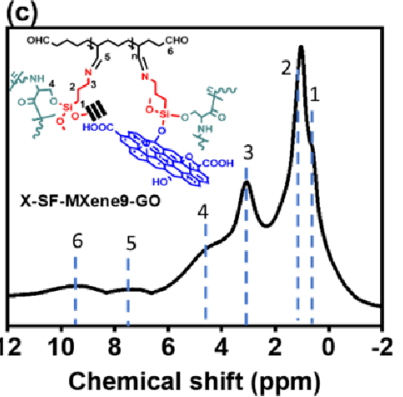

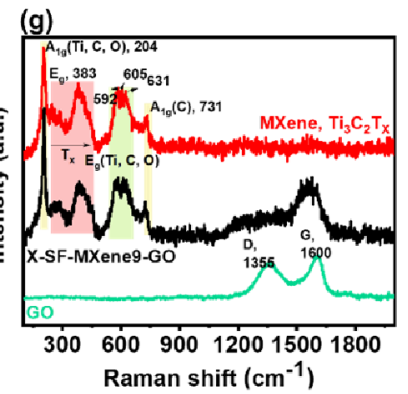

Figure 4. (a) Liquid-state ${ }^{1} \mathrm{H}$ NMR spectra of SF and SilSF; (b) ATR-FTIR spectra of X-SF and X-SF-MXene9-GO; (c) solid-state mass ${ }^{1} \mathrm{H}$ NMR spectrum of X-SF-MXene9-GO; (d) XRD patterns of as-prepared MXene and X-SF-MXene9-GO; (e) XPS survey spectra and (f) XPS C 1s highresolution spectra of X-SF-MXene9; and (g) Raman spectra of MXene, GO, and X-SF-MXene9-GO composite foams.

$\mathrm{kPa}$ (X-SF-MXene5-GO). It is evident that by increasing the content of X-SF and MXene in the composite foams, the elastic modulus and the maximum strength were enhanced. The covalent cross-linking of SF in the composite and further incorporation of GO and MXene nanosheets not only reinforced the highly porous structure of the resultant foams but also enhanced the elasticity. A strain relaxation was also observed during five loading and unloading compression cycles for all samples at $30 \%$ of the strain (Figure 3b,e,h). Besides, repeated compression by hand further substantiated the high compressibility and elasticity of the developed foams at the strain values mentioned above (cf. Video S1). Figure 3j shows the schematic hierarchical structure of the composite foams and the strain relaxation behavior of the composite foams during the cyclic compression-decompression for $\varepsilon<30 \%$. For the same samples, increasing the compressive loads, for $\varepsilon>$ $30 \%$, the sample decompression was very slow and at $\varepsilon=80 \%$, the samples were entirely deformed.

3.2. Chemical and Crystal Structures. The surface amino functional groups in the SF molecular structure are scarce; for example, lysine amino acid comprises only $\sim 2 \mathrm{mg}$ $\mathrm{g}_{\mathrm{SF}}{ }^{-1}$. Therefore, for cross-linking of SF with GA, surface chemistry of SF was first modified with amino-functionalized silane, APTES, through condensation of the dangling hydroxyl side chain of SF with the ethoxy group in APTES to modify the surface with more amino functionalities. The amino-modified SF was called SilSF in this study. The incorporation of the amino functionalities into SilSF is evident from ${ }^{1} \mathrm{H}$ NMR spectra shown for plain SF and SilSF in Figure 4a. Besides the characteristic peaks belonging to $\mathrm{SF}^{47}$ the SilSF was accompanied by extra chemical shifts at $0.5(2 \mathrm{H}, \mathrm{t}), 1.08$ $(2 \mathrm{H}, \mathrm{Q}), 1.68(2 \mathrm{H}, \mathrm{Q})$, and $3.54 \mathrm{ppm}(2 \mathrm{H}, \mathrm{Q})$ due to the incorporation of APTES. The cross-linking with GA was substantiated with solid-state mass ${ }^{1} \mathrm{H}$ NMR and the ATRFTIR spectroscopies shown in Figure $4 b, c$, respectively. As shown in Figure $4 \mathrm{~b}$, the composite structures were further confirmed with the presence of characteristic bands of $v_{\text {as }}$
$(-\mathrm{Si}-\mathrm{O}-\mathrm{C}-), v_{\text {as }}(-\mathrm{Si}-\mathrm{O}-\mathrm{Si}-)$, and $v_{\text {as }}(-\mathrm{Ti}-\mathrm{O})$ at 1052 , 1102 , and $662 \mathrm{~cm}^{-1}$, respectively. In addition, in all composites, the X-SF was characterized by amide I ( $v_{\text {as }}$ $\left.(\mathrm{C}=\mathrm{O}), 1618-1640 \mathrm{~cm}^{-1}\right)$, amide II $\left(\delta_{\mathrm{s}}(\mathrm{N}-\mathrm{H})\right.$ deformations/bending $\left.1512-1544 \mathrm{~cm}^{-1}\right)$, and amide III $\left(v_{\text {as }}(\mathrm{C}-\mathrm{N})\right.$, $\left.1230 \mathrm{~cm}^{-1}\right)$ vibrations. ${ }^{12}$ With cross-linking of SilSF with GA, two different double bonds appear in the structure of SilSF$\mathrm{GA}$, i.e., $-\mathrm{C}=\mathrm{C}-$ bonds from $\mathrm{GA}$ and $-\mathrm{C}=\mathrm{N}-$ from the cross-linking reaction between the amine groups in SilSF and aldehyde groups in GA. These double bonds form a conjugated planar structure in the X-SF, which enabled it to become autofluorescent. The peak at $1585 \mathrm{~cm}^{-1}$ is associated with the $-\mathrm{C}=\mathrm{C}-$ bonds, and the peak at $1658 \mathrm{~cm}^{-1}$ is attributed to the imine bonds $(-\mathrm{C}=\mathrm{N}-)$, which is also designated as peak 5 at $7.6 \mathrm{ppm}$ in the solid-state ${ }^{1} \mathrm{H}$ NMR mass spectrum in Figure 4c.

The surface termination groups in MXene $\left(\mathrm{T}_{x}:-\mathrm{OH},-\mathrm{O}\right.$, and $-F$ ) not only enabled its nanodispersibility inside the $\mathrm{X}$ SF aqueous solution but also resulted in its further dipoledipole interactions and hydrogen bondings with the $-\mathrm{COOH}$ surface termination of $\mathrm{GO}$ and the $-\mathrm{OH}$ side chain of $\mathrm{X}-\mathrm{SF}$ and its subsequent homogeneous mixing at the nanoscale before freeze-casting.

According to the XRD patterns in Figure 4d, MXene nanosheets were detected in the foam matrix through their characteristic peaks of (002) at 5.9. ${ }^{48}$ For the as-synthesized MXene, the typical diffraction peak (002) appeared at around $2 \theta=7.01^{\circ}$, indicating that the interlayer distance of MXene was about $1.3 \mathrm{~nm}$ according to the Bragg equation: $2 \mathrm{~d} \sin \theta=$ $n \lambda$. After incorporation of MXene into the foam, this peak shifted to a lower angle around $2 \theta=5.9^{\circ}$, indicating that interlayer spacings expanded to about $1.5 \mathrm{~nm}$. This was also confirmed with the XPS survey spectra in Figure 4e, indicating the elemental compositions of $\mathrm{C}, \mathrm{N}, \mathrm{Ti}, \mathrm{O}$, and $\mathrm{F}$ and the valence states of the elements of MXene and X-SF in the composite matrix. The $\mathrm{Ti} 2 \mathrm{p}$ high-resolution spectrum in Figure S1a exhibits binding energies of 455.3 and $461.4 \mathrm{eV}$ 
(a)

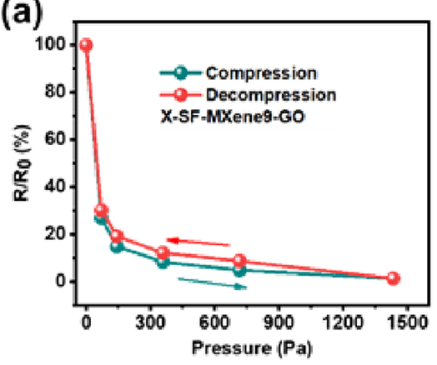

(d)

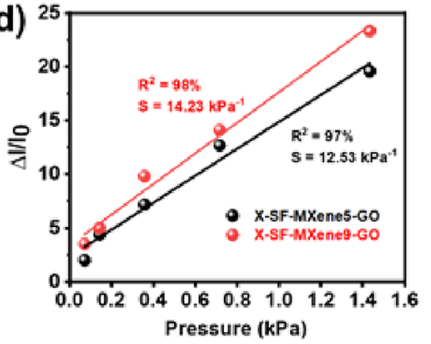

(b)

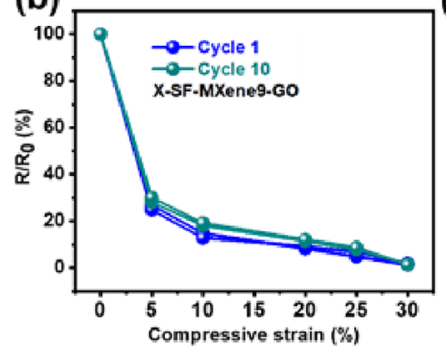

(e)

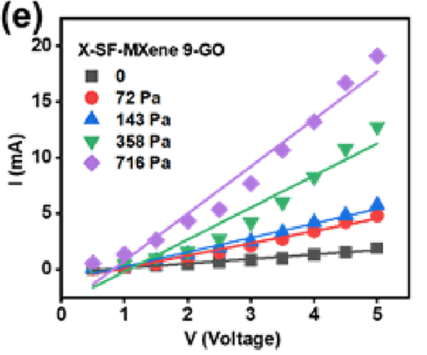

(c) 12
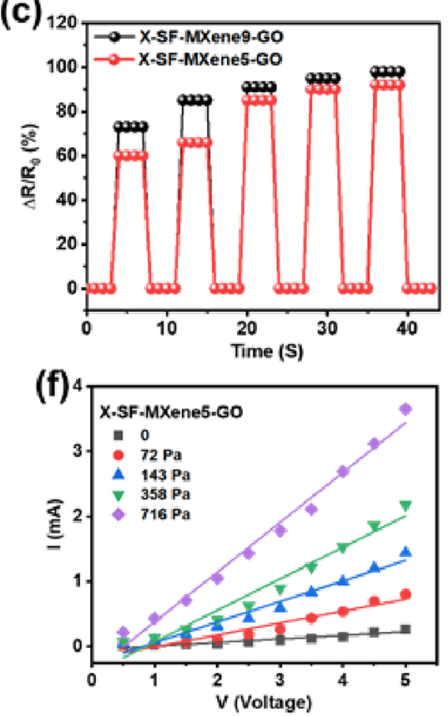

(g)

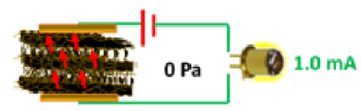

(i)
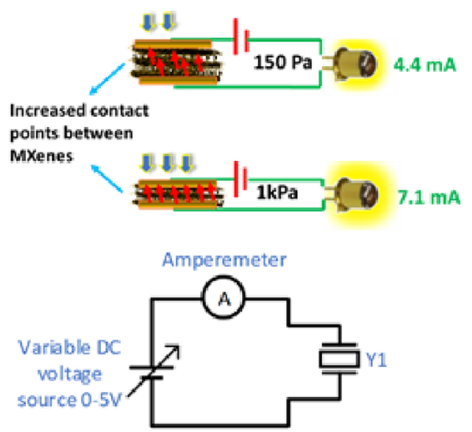

(k)

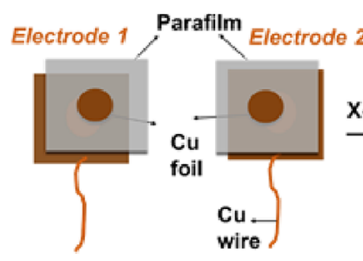

(h)
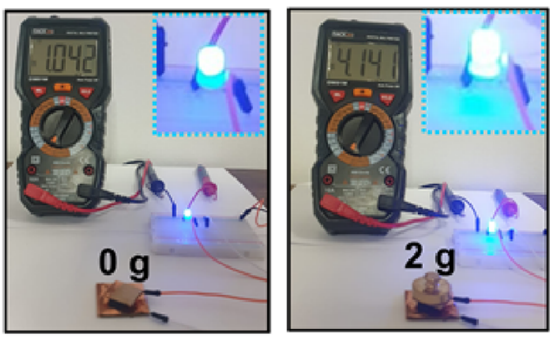

(j)

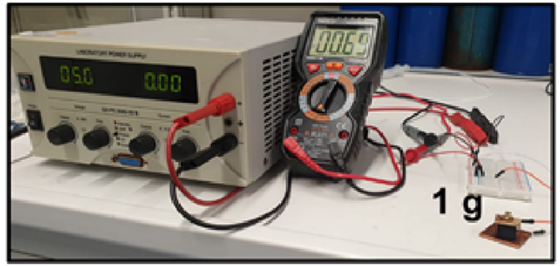

(I)

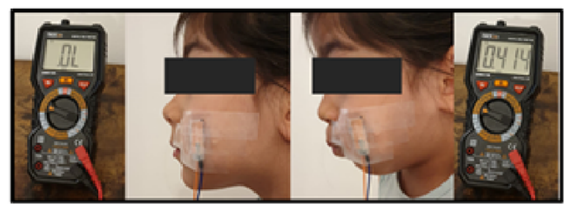

Figure 5. The pressure-sensing performance of the X-SF-MXene-GO. (a) Electrical resistance vs pressure. (b) Electrical resistance vs compressive strain. (c) $R-T$ curves of the X-SF-MXene-GO foam with two different ratios of MXene/X-SF (5:1 and 9:1) under five various external forces. (d) Relative current changes with respect to the applied pressure, where the two curves represent the different ratios of MXene:X-SF (9:1 and 5:1). (e) $I-V$ curves of X-SF-MXene9-GO and (f) X-SF-MXene5-GO under varying pressures. (g) Proposed mechanism of strain (or pressure) sensitive conductivity. (h) Effect of compression and decompression of X-SF-MXene-GO on the brightness of an LED. (i) and (j) The scheme and the device installation for evaluation of X-SF-MXene9-GO performance under varying voltages and external pressures and reporting $I-V$ curves. (k) Assembling the electrode for muscle movement and (l) resistance response of a piece of foam by attaching the sensor to the human cheek for evaluation of the sensing performance of the foam sensor for the human muscle movement.

corresponding to $\mathrm{Ti} 2 \mathrm{p}(3 / 2)$ and $\mathrm{Ti} 2 \mathrm{p}(1 / 2)$ of the $\mathrm{Ti}-\mathrm{C}$ bonds. Moreover, the peaks located at 456.3 and $459.3 \mathrm{eV}$ correspond to $\mathrm{Ti} 2 \mathrm{p}(3 / 2)$ of $\mathrm{Ti}-\mathrm{O}$ and $\mathrm{Ti}-\mathrm{F}$. As shown in Figure $4 \mathrm{f}$, the $\mathrm{C} 1 \mathrm{~s}$ peaks at 282.1 and $284.8 \mathrm{eV}$ correspond to the $\mathrm{Ti}-\mathrm{C}$ and $\mathrm{C}-\mathrm{C}$ bonds of $\mathrm{X}-\mathrm{SF}$, confirming the presence of the carbon and carbonated species of the X-SF-MXene9 composite. ${ }^{49}$ The $\mathrm{O} 1 \mathrm{~s}$ peaks located at 530.1, 531, and 532.5 $\mathrm{eV}$ correspond to $\mathrm{O} 1 \mathrm{~s}$ in $\mathrm{Ti}-\mathrm{O}-$, carbonyl, and hydroxyl groups in the composite (cf. Figure S1b). In addition, the F $1 \mathrm{~s}$ intense peak at $685.5 \mathrm{eV}$ is attributed to $\mathrm{Ti}_{3} \mathrm{C}_{2} \mathrm{~F} .{ }^{50}$ The Raman spectrum of MXene (Figure $4 \mathrm{~g}$ ) can be separated into three active Raman modes/regions corresponding to $\mathrm{A}_{1 \mathrm{~g}}(\mathrm{Ti}, \mathrm{C}$, and $\mathrm{O})$, at $201 \mathrm{~cm}^{-1}$, and $\mathrm{E}_{\mathrm{g}}(\mathrm{Ti}, \mathrm{C}$, and $\mathrm{O}$ ) peaks at 230$470 \mathrm{~cm}^{-1}$, which are in-plane and out-of-plane vibrations of $\mathrm{Ti}$ in the outer layer and carbon and surface groups, respectively. In-plane $E_{g}$ vibrations at $230-470 \mathrm{~cm}^{-1}$ also represent the surface functional groups $\left(\mathrm{T}_{x}\right)$ attached to the $\mathrm{Ti}$ atoms. This region is usually used for probing the surface chemistry and the type of functional groups on MXene. The region between 591 and $731 \mathrm{~cm}^{-1}$ is assigned to the carbon vibrations in both $E_{g}$ and $\mathrm{A}_{1 \mathrm{~g}}$ modes. ${ }^{51}$ All of these vibrational modes could also be detected in the composite X-SF-MXene9-GO, with additional 
(a)

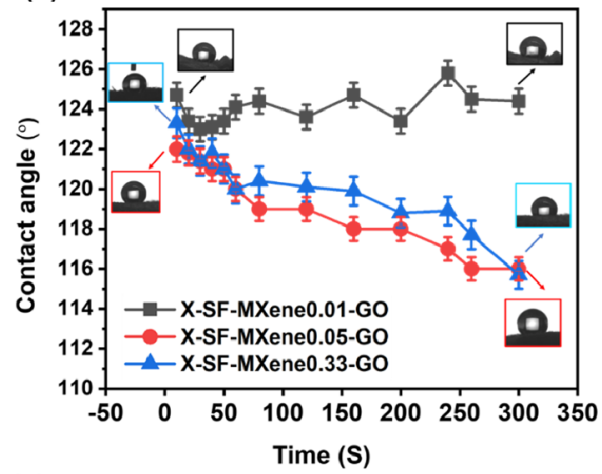

(c)

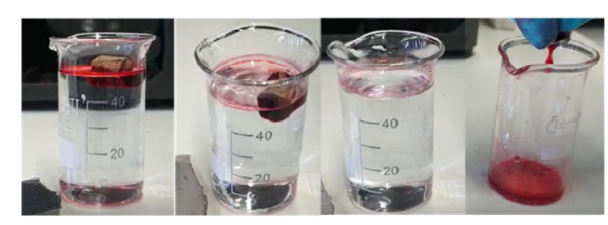

(b)

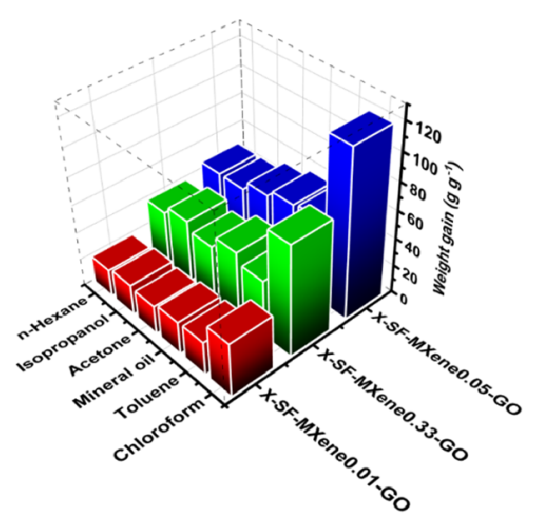

(d)

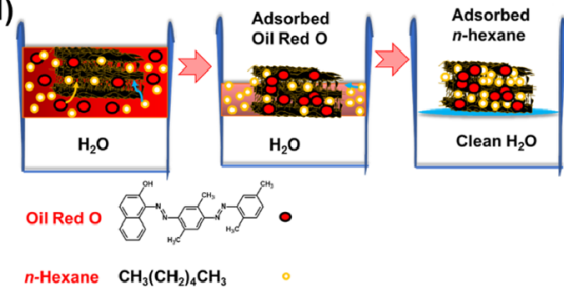

Figure 6. (a) Variation of the WCA values vs time for the composite foams with three different formulations. (b) Oil and organic absorption performance of the composite foams based on the composites' weight gain. (c) Separation of a three-component $n$-hexane-Oil-red O-water mixture with X-SF-MXene0.05-GO through the absorption-squeezing technique. (d) Schematic of the mechanism of separation of the three components of $n$-hexane-Oil-red $\mathrm{O}$-water with absorption and separation of the mixture.

vibration modes for $\mathrm{GO}$ at $1600 \mathrm{~cm}^{-1}$ ( $\mathrm{G}$ band) and 1355 $\mathrm{cm}^{-1}$ ( $\mathrm{D}$ band). The $\mathrm{D}$ and $\mathrm{G}$ bands explain the structural defect (disorder-induced mode) and first-order scattering from the $\mathrm{sp}^{2}$ carbon bonding, respectively. The ratios of the $\mathrm{D}$ band to the $\mathrm{G}$ band intensity $(I)\left(I_{\mathrm{D}} / I_{\mathrm{G}}\right)$ values in GO and X-SFMxene9-GO are 0.88 and 0.74 , respectively, which indicated that the X-SF and MXene increased the local defects and disorder of GO.

3.3. Pressure-Sensing Properties. MXene incorporation into the foam due to its metallic electrical conductivity is very pivotal. Various MXene-to-X-SF ratios in composite foams caused different electrical responses and pressure sensitivity. For the formulation in which the MXene/X-SF ratio was less than 0.33 , the organic part in the composite was the dominated phase in the composites, and therefore, the electrical response was also relatively compromised. The synergistic combination of electrical conductivity and mechanical resilience was only obtained for samples with higher MXene/X-SF ratios of 5:1 and 9:1. As shown in Figure 5a,b, the electrical resistance of the X-SF-MXene9-GO foam decreased with an increase of compressive strain in a strain range of $0-30 \%$ and the pressure up to $1.43 \mathrm{kPa}$. This experiment was performed by a gradual increase in the stress/load on the composite foams and monitoring the resistance changes upon applying the pressure and decreasing the resistance. For the X-SF-MXene9-GO sample, the percentage decreases of electrical resistances were $73.16 \%, 91.7 \%, 95.1 \%$, and $98.7 \%$ at the compressive strain values of $1 \%, 5 \%, 20 \%$, and $30 \%$, respectively. Also, the elastic skeleton springs back after decompression, which made the electrical resistance of X-SF-MXene9-GO foams recoverable. The diverse low pressures of $71 \mathrm{~Pa}, 143 \mathrm{~Pa}, 358 \mathrm{~Pa}, 716 \mathrm{~Pa}$, and $1.43 \mathrm{kPa}$ can be detected with fast responses, indicating a high and linear sensitivity for pressure detection (cf. Figure $5 \mathrm{c}, \mathrm{d}$ ). A gentle touch usually relates to $1-10 \mathrm{kPa}$. According to Figure $5 \mathrm{c}$, the electrical resistance also recovered fast $(\sim 3 \mathrm{~s})$ during the decompression process up to 10 cycles. The linear relationship between $\Delta \mathrm{I} / \mathrm{I}_{0}$ and pressure determines the sensor output and sensitivity. The sensitivity $(S)$ is defined as eq 1

$$
\mathrm{S}=\left(\Delta I / I_{0}\right) / \Delta \mathrm{P}
$$

where $\Delta I$ is the change in the current under an applied pressure, $I_{0}$ is the initial current without applied pressure, and $\Delta P$ is the applied pressure change.

Despite most of the reported carbon-based pressure-sensing materials, such as the carbon aerogel, ${ }^{52-54}$ flexible substrateloaded carbon, ${ }^{55,56}$ and carbon film, ${ }^{57-59}$ the present foams could maintain a better linear sensitivity, which are 14.23 and $12.53 \mathrm{kPa}^{-1}$ under $1.4 \mathrm{kPa}$ for X-SF-MXene9-GO and X-SFMXene5-GO, respectively. The reported sensitivity values were also higher than the values obtained from the MXene/GO composite foams reported by $\mathrm{Ma}$ et al. ${ }^{29}\left(S=4.05 \mathrm{kPa}^{-1}\right.$ at pressure $\sim 1 \mathrm{kPa})$. At a constant concentration of GO and X$\mathrm{SF}$, with an increased ratio of MXene to X-SF from 5 to 9 , more MXene nanosheets were connected; therefore, the sensitivity of the hybrid foam increased due to the increase of the conductive path. This is due to the fact that the pore walls (brick and mortar) of the X-SF-MXene5,9-GO were made up of MXene and GO, which are intertwined together with the X-SF matrix as glue and support the overall network compressibility.

Due to the hierarchical and homogeneous distribution of MXene single sheets in the foam structure, once the foam is compressed, the contact area of MXene nanosheets is increased, leading to a decrease in the resistance and consequently an increase in the current. In addition, the sensor could sense the continuous increase of the applied force or pressure and respond to it as a steady increase in the current density. The almost linear relation of the $I-V$ curves (Figure $5 \mathrm{e}, \mathrm{f}$ ) upon varying the voltage values from 0.5 to $5 \mathrm{~V}$ (Figure $5 \mathrm{i}, \mathrm{j}$ ) suggested that ohmic contacts between X-SF-MXene9GO and cupper electrodes were formed, and the sensor performance was according to Ohm's law. With the increase of 
the pressure, the slope of $I-V$ curves increased, indicating the continuous decrease of the sensor's resistance. As presented in Figure $5 \mathrm{~g}$, more contacts among conductive MXene nanosheets in X-SF-MXene9-GO foams were produced upon compression, which subsequently decreased the electrical resistance.

To better visualize the effect of compression on the foam resistance, we connected an X-SF-MXene9-GO composite foam to a light-emitting diode (LED) and a battery circuit. The brightness of the LED increased upon compression and decreased upon decompression of the foam, which further confirmed the pressure-sensitive conductivity (cf. Figure $5 \mathrm{~h}$ and Video S2).

To evaluate the performance of sensors for real-time sensing of human movements, a thin cylindrical foam was fixed between two flexible copper-based electrodes and attached to the human cheek. As it is evident from Figure 5k,l, the X-SFMXene9-GO foam sensors also showed competence in detecting the body's small motion and biosignals. For example, they can distinctly sense the human face expression upon blowing the cheek muscles and show it as changes in the output resistance signals. This sensing performance is particularly important to diagnose some diseases and substantiate the potential of foams for various wearable applications.

3.4. Hydrophobicity and Oil/Water Separation Performance. The hydrophobicity was also effectively improved by a simple chemical vapor hydrophobization of the developed composite foams with HMDS in a closed chamber at a high temperature for $24 \mathrm{~h}$ (see Figure $1 \mathrm{~g}$ ). The saturated vapor of HMDS diffused into the open and interconnected porous structure of the composites and reacted with free surface hydroxyl groups of the pore surface, which originated from the MXene nanosheets and SF functionalities. The vapor phase modification of the final dried samples developed from directional freeze-casting of the precursors' solution without having the gel phase is particularly advantageous as it minimizes the utilization of the organic solvent upon surface treatment. In contrast to the untreated composite foams, in which the water droplet immediately diffused into the porous structure and wetted the composites, the hydrophobized samples with various MXene/X-SF ratios indicated a better hydrophobicity as well as oleophilic properties. This is evident from the WCA values shown in Figure 6a. The WCAs of the composite foams with three different MXene/X-SF ratios of $0.01,0.05$, and 0.33 were $124.8^{\circ}, 121.8^{\circ}$, and $123.3^{\circ}$, respectively. The higher the X-SF content in the composite, the larger the WCA values due to the greater extent of available hydroxyl groups treated with trimethylsilyl moieties. This was also the same with the higher MXene content in the composite, which can provide more available hydroxyl groups for hydrophobization; for example, MXene/X-SF ratios of 0.05 and 0.33 had the same X-SF and GO but different MXene contents. With a higher concentration of X-SF (e.g., MXene/ $\mathrm{X}$-SF: 0.01$)$ in the composite, the porous structure was denser $\left(\rho_{\mathrm{b}}=0.06 \mathrm{~g} \mathrm{~cm}^{-3}\right)$; therefore, the dispensed water droplet was also more stable after $5 \mathrm{~min}$ of placing on the composite surface without diffusing into the monolith. The composite with a low X-SF concentration (MXene/X-SF: 0.05 and 0.33 ) had a low bulk density $\left(0.025\right.$ and $\left.0.029 \mathrm{~g} \mathrm{~cm}^{-3}\right)$ with a more open porous structure and larger pore channels; therefore, despite hydrophobicity of the pore surface, the water droplet gradually diffused into the pore channels, and the WCA decreased to $\sim 116^{\circ}$.

Thanks to the highly open porous structure with ultralow density, hydrophobicity, and high compressibility, the X-SFMXene-GO foams exhibited an excellent absorption performance for organic liquids and oils. As shown in Figure $6 \mathrm{~b}$, the resulting foams possessed high absorption capacities for organic solvents and oils such as chloroform, which can be absorbed in the composite foams. The weight gains of X-SFMXene0.01-GO $\left(\rho_{\mathrm{b}}=0.06 \mathrm{~g} \mathrm{~cm}^{-3}\right)$, X-SF-MXene0.05-GO $\left(\rho_{\mathrm{b}}\right.$ $\left.=0.025 \mathrm{~g} \mathrm{~cm}^{-3}\right)$, and X-SF-MXene0.33-GO $\left(\rho_{\mathrm{b}}=0.029 \mathrm{~g}\right.$ $\mathrm{cm}^{-3}$ ) after absorbing chloroform, $n$-hexane, and mineral oil were in the ranges of 20-60, 39-120, and 24-58 $\mathrm{g} \mathrm{g}^{-1}$, respectively. The obtained absorption capacities of the composites were in the absorption range of previously reported aerogels in the literature. ${ }^{13,15,31}$ In addition, X-SF-MXene0.05GO could effectively separate dye, oil, and water (such as $n$ hexane, Oil-red $\mathrm{O}$, and water) from the three-component oildye-water mixtures in a single absorption step (Figure 6d).

\section{CONCLUSIONS}

In summary, we have successfully fabricated SF-MXene-GO composite foams with hierarchical architectures mimicking the nacre microstructure using a well-established and versatile bioinspired bidirectional freeze-casting approach. The fabricated bioinspired architectures were composed of lamellae and interconnected bridges, which can confer exceptional strength and resilience to the composite foam. This structural complexity, together with improved mechanical resilience, is usually hard to achieve for porous materials processed by conventional synthesis and fabrication techniques such as solgel and hard templating approaches. The composite foams developed in this study exhibited a tunable and highly porous structure composed of inter-cross-linked SF chains, which were also intertwined with MXene and GO nanosheets. The X-SFMXene foams combined an ultralow density $\left(6-60 \mathrm{mg} \mathrm{cm}^{-3}\right)$, hydrophobicity (WCA up to $124^{\circ}$ ), compressibility (reversible compressibility up to $30 \%$ without failure and ultimate compression more than $80 \%$ ), high absorption capacity for organic liquids (up to $\sim 120 \mathrm{~g} \mathrm{~g}^{-1}$ ), efficient multicomponent oil/dye/organic solvent separation, and pressure-sensing capability. Besides, the strain/pressure sensors based on XSF-MXene-GO are highly sensitive and can be used for highperformance flexible sensing arrays for the detection of strain (up to $50 \%)$ and pressure ( $\sim 1 \mathrm{~Pa}$ to $2 \mathrm{kPa})$ distributions.

Finally, the present study provides the essential concepts to translate the natural porous architectures into synthetic foams to improve their mechanical properties and functions with a high level of control on the microarchitecture. The fabricated flexible multifunctional porous nanocomposites show promising applications in flexible pressure sensors/electronic skins, pollutant separation, and other high-performance applications.

\section{ASSOCIATED CONTENT}

\section{sI Supporting Information}

The Supporting Information is available free of charge at https://pubs.acs.org/doi/10.1021/acsami.1c09675.

High-resolution XPS spectra of O 1s (a) and Ti 2p (b) and explanation about used characterization methods (PDF, MP4, and MP4) 


\section{AUTHOR INFORMATION}

\section{Corresponding Author}

Hajar Maleki - Institute of Inorganic Chemistry, Department of Chemistry, University of Cologne, 50939 Cologne, Germany; (1) orcid.org/0000-0002-2813-4700; Email: h.maleki@uni-koeln.de

\section{Authors}

Mohsen Bandar Abadi - GE Renewable Energy, General Electric, 48499 Salzbergen, Germany

Rene Weissing - Institute of Inorganic Chemistry, Department of Chemistry, University of Cologne, 50939 Cologne, Germany

Michael Wilhelm - Institute of Inorganic Chemistry, Department of Chemistry, University of Cologne, 50939 Cologne, Germany

Yan Demidov - Institute of Inorganic Chemistry, Department of Chemistry, University of Cologne, 50939 Cologne, Germany

Jaqueline Auer - University of Applied Sciences Upper Austria, 4600 Wels, Austria

Samaneh Ghazanfari - Aachen-Maastricht Institute for Biobased Materials (AMIBM), Faculty of Science and Engineering, Maastricht University, 6167 RD Geleen, The Netherlands; Department of Biohybrid and Medical Textiles (BioTex), AME-Helmholtz Institute for Biomedical Engineering, RWTH Aachen University, 52074 Aachen, Germany

Babak Anasori - Department of Mechanical and Energy Engineering and Integrated Nanosystems Development Institute, Purdue School of Engineering and Technology, Indiana University-Purdue University Indianapolis, Indianapolis, Indiana 46202, United States; (1) orcid.org/ 0000-0002-1955-253X

Sanjay Mathur - Institute of Inorganic Chemistry, Department of Chemistry, University of Cologne, 50939 Cologne, Germany; (1) orcid.org/0000-0003-2765-2693

Complete contact information is available at: https://pubs.acs.org/10.1021/acsami.1c09675

\section{Notes}

The authors declare no competing financial interest.

\section{ACKNOWLEDGMENTS}

H.M. would like to acknowledge the support of the German Aerospace Center (DLR) and the Association of the Chemical Industry, the Chemical Industry Fund for the financial support. H.M. would also like to thank Prof. Meerholz and Ruth Bruker for SEM analysis support, Prof. Jahn for Raman spectrometer usage, and Tim Ludwig for kindly providing the GO powder. The micro-CT investigation was supported by the project "Multimodal and in situ characterization of inhomogeneous materials" (MiCi) funded by the federal government of Upper Austria and the European Regional Development Fund (EFRE) in the framework of the EU-Program (no. IWB2020).

\section{REFERENCES}

(1) Lee, S.; Shin, S.; Lee, S.; Seo, J.; Lee, J.; Son, S.; Cho, H. J.; Algadi, H.; Al-Sayari, S.; Kim, D. E.; Lee, T. Ag Nanowire Reinforced Highly Stretchable Conductive Fibers for Wearable Electronics. Adv. Funct. Mater. 2015, 25, 3114-3121.
(2) Li, J.; Bao, R.; Tao, J.; Peng, Y.; Pan, C. Recent Progress in Flexible Pressure Sensor Arrays: From Design to Applications. J. Mater. Chem. C 2018, 6, 11878-11892.

(3) Zang, Y.; Zhang, F.; Di, C.; Zhu, D. Advances of Flexible Pressure Sensors toward Artificial Intelligence and Health Care Applications. Mater. Horiz. 2015, 2, 140-156.

(4) Nyström, G.; Roder, L.; Fernández-Ronco, M. P.; Mezzenga, R. Amyloid Templated Organic-Inorganic Hybrid Aerogels. Adv. Funct. Mater. 2018, 28, No. 1703609.

(5) Hamedi, M.; Karabulut, E.; Marais, A.; Herland, A.; Nyström, G.; Wågberg, L. Nanocellulose Aerogels Functionalized by Rapid Layer-by-Layer Assembly for High Charge Storage and Beyond. Angew. Chem., Int. Ed. 2013, 52, 12038-12042.

(6) Carlsson, D. O.; Nyström, G.; Zhou, Q.; Berglund, L. A.; Nyholm, L.; Strømme, M. Electroactive Nanofibrillated Cellulose Aerogel Composites with Tunable Structural and Electrochemical Properties. J. Mater. Chem. 2012, 22, 19014-19024.

(7) Zhuo, H.; Hu, Y.; Tong, X.; Chen, Z.; Zhong, L.; Lai, H.; Liu, L.; Jing, S.; Liu, Q.; Liu, C.; Peng, X.; Sun, R. A. Supercompressible, Elastic, and Bendable Carbon Aerogel with Ultrasensitive Detection Limits for Compression Strain, Pressure, and Bending Angle. Adv. Mater. 2018, 30, No. 1706705.

(8) Xu, X.; Zhou, J.; Nagaraju, D. H.; Jiang, L.; Marinov, V. R.; Lubineau, G.; Alshareef, H. N.; Oh, M. Flexible, Highly Graphitized Carbon Aerogels Based on Bacterial Cellulose/Lignin: Catalyst-Free Synthesis and Its Application in Energy Storage Devices. Adv. Funct. Mater. 2015, 25, 3193-3202.

(9) Hu, D.; Huang, X.; Li, S.; Jiang, P. Flexible and Durable Cellulose/MXene Nanocomposite Paper for Efficient Electromagnetic Interference Shielding. Compos. Sci. Technol. 2020, 188, No. 107995.

(10) Cao, W.-T.; Chen, F.-F.; Zhu, Y.-J.; Zhang, Y.-G.; Jiang, Y.-Y.; Ma, M.-G.; Chen, F. Binary Strengthening and Toughening of MXene/Cellulose Nanofiber Composite Paper with Nacre-Inspired Structure and Superior Electromagnetic Interference Shielding Properties. ACS Nano 2018, 12, 4583-4593.

(11) Zeng, Z.; Wu, T.; Han, D.; Ren, Q.; Siqueira, G.; Nyström, G. Ultralight, Flexible, and Biomimetic Nanocellulose/Silver Nanowire Aerogels for Electromagnetic Interference Shielding. ACS Nano 2020, 14, 2927-2938.

(12) Maleki, H.; Montes, S.; Hayati-Roodbari, N.; Putz, F.; Huesing, N. Compressible, Thermally Insulating, and Fire Retardant Aerogels through Self-Assembling Silk Fibroin Biopolymers Inside a Silica Structure-An Approach towards 3D Printing of Aerogels. ACS Appl. Mater. Interfaces 2018, 10, 22718-22730.

(13) Maleki, H.; Whitmore, L.; Hüsing, N. Novel Multifunctional Polymethylsilsesquioxane-Silk Fibroin Aerogel Hybrids for Environmental and Thermal Insulation Applications. J. Mater. Chem. A 2018, $6,12598-12612$.

(14) Maleki, H.; Huesing, N. Silica-Silk Fibroin Hybrid (Bio)Aerogels: Two-Step versus One-Step Hybridization. J. Sol-Gel Sci. Technol. 2019, 98, 430-438.

(15) Bruder, V.; Ludwig, T.; Opitz, S.; Christoffels, R.; Fischer, T.; Maleki, H. Hierarchical Assembly of Surface Modified Silk Fibroin Biomass into Micro-, and Milli-Metric Hybrid Aerogels with CoreShell, Janus, and Composite Configurations for Rapid Removal of Water Pollutants. Adv. Mater. Interfaces 2021, 8, No. 2001892.

(16) Maleki, H.; Shahbazi, M.-A.; Montes, S.; Hosseini, S. H.; Eskandari, M. R.; Zaunschirm, S.; Verwanger, T.; Mathur, S.; Milow, B.; Krammer, B.; Hüsing, N. Mechanically Strong Silica-Silk Fibroin Bioaerogel: A Hybrid Scaffold with Ordered Honeycomb Micromorphology and Multiscale Porosity for Bone Regeneration. ACS Appl. Mater. Interfaces 2019, 11, 17256-17269.

(17) Rockwood, D. N.; Preda, R. C.; Yücel, T.; Wang, X.; Lovett, M. L.; Kaplan, D. L. Materials Fabrication from Bombyx mori Silk Fibroin. Nat. Protoc. 2011, 6, 1612-1631.

(18) Qin, Y.; Peng, Q.; Ding, Y.; Lin, Z.; Wang, C.; Li, Y.; Xu, F.; Li, J.; Yuan, Y.; He, X.; Li, Y. Lightweight, Superelastic, and Mechanically Flexible Graphene/Polyimide Nanocomposite Foam for Strain Sensor Application. ACS Nano 2015, 9, 8933-8941. 
(19) Marcano, D. C.; Kosynkin, D. V.; Berlin, J. M.; Sinitskii, A.; Sun, Z.; Slesarev, A.; Alemany, L. B.; Lu, W.; Tour, J. M. Improved Synthesis of Graphene Oxide. ACS Nano 2010, 4, 4806-4814.

(20) Wicklein, B.; Kocjan, A.; Salazar-Alvarez, G.; Carosio, F.; Camino, G.; Antonietti, M.; Bergström, L. Thermally Insulating and Fire-Retardant Lightweight Anisotropic Foams Based on Nanocellulose and Graphene Oxide. Nat. Nanotechnol. 2015, 10, 277-283.

(21) Wan, C.; Li, J. Graphene Oxide/Cellulose Aerogels Nanocomposite: Preparation, Pyrolysis, and Application for Electromagnetic Interference Shielding. Carbohydr. Polym. 2016, 150, 172179.

(22) Naguib, M.; Kurtoglu, M.; Presser, V.; Lu, J.; Niu, J.; Heon, M.; Hultman, L.; Gogotsi, Y.; Barsoum, M. W. Two-Dimensional Nanocrystals Produced by Exfoliation of $\mathrm{Ti}_{3} \mathrm{AlC}_{2}$. Adv. Mater. 2011, 23, 4248-4253.

(23) Naguib, M.; Mochalin, V. N.; Barsoum, M. W.; Gogotsi, Y. 25th Anniversary Article: MXenes: A New Family of Two-Dimensional Materials. Adv. Mater. 2014, 26, 992-1005.

(24) Mathis, T. S.; Maleski, K.; Goad, A.; Sarycheva, A.; Anayee, M.; Foucher, A. C.; Hantanasirisakul, K.; Shuck, C. E.; Stach, E. A.; Gogotsi, Y. Modified MAX Phase Synthesis for Environmentally Stable and Highly Conductive $\mathrm{Ti}_{3} \mathrm{C}_{2}$ MXene. ACS Nano 2021, 15, 6420-6429.

(25) Lipatov, A.; Lu, H.; Alhabeb, M.; Anasori, B.; Gruverman, A.; Gogotsi, Y.; Sinitskii, A. Elastic Properties of $2 \mathrm{D} \mathrm{Ti}_{3} \mathrm{C}_{2} \mathrm{~T}_{\mathrm{x}}$ MXene Monolayers and Bilayers. Sci. Adv. 2018, 4, No. eaat0491.

(26) Wyatt, B. C.; Rosenkranz, A.; Anasori, B. 2D MXenes: Tunable Mechanical and Tribological Properties. Adv. Mater. 2021, 33, No. 2007973.

(27) Gogotsi, Y.; Anasori, B. The Rise of MXenes. ACS Nano 2019, 13, 8491-8494.

(28) Bi, L.; Yang, Z.; Chen, L.; Wu, Z.; Ye, C. Compressible AgNWs $/ \mathrm{Ti}_{3} \mathrm{C}_{2} \mathrm{~T}_{\mathrm{x}}$ MXene Aerogel-Based Highly Sensitive Piezoresistive Pressure Sensor as Versatile Electronic Skins. J. Mater. Chem. A 2020, 8, 20030-20036.

(29) Ma, Y.; Yue, Y.; Zhang, H.; Cheng, F.; Zhao, W.; Rao, J.; Luo, S.; Wang, J.; Jiang, X.; Liu, Z.; Liu, N.; Gao, Y. 3D Synergistical MXene/Reduced Graphene Oxide Aerogel for a Piezoresistive Sensor. ACS Nano 2018, 12, 3209-3216.

(30) Zu, G.; Kanamori, K.; Maeno, A.; Kaji, H.; Nakanishi, K.; Shen, J. Ambient-Dried Highly Flexible Copolymer Aerogels and Their Nanocomposites with Polypyrrole for Thermal Insulation, Separation, and Pressure Sensing. Polym. Chem. 2019, 10, 4980-4990.

(31) Zu, G.; Kanamori, K.; Nakanishi, K.; Lu, X.; Yu, K.; Huang, J.; Sugimura, H. Superelastic Multifunctional Aminosilane-Crosslinked Graphene Aerogels for High Thermal Insulation, Three-Component Separation, and Strain/Pressure-Sensing Arrays. ACS Appl. Mater. Interfaces 2019, 11, 43533-43542.

(32) Bai, H.; Chen, Y.; Delattre, B.; Tomsia, A. P. Bidirectional Freeze Casting for Fabricating Lamellar Structures. US20170100857A1. 2017.

(33) Bai, H.; Chen, Y.; Delattre, B.; Tomsia, A. P.; Ritchie, R. O. Bioinspired Large-Scale Aligned Porous Materials Assembled with Dual Temperature Gradients. Sci. Adv. 2015, 1, No. e1500849.

(34) Shao, G.; Hanaor, D. A. H.; Shen, X.; Gurlo, A. Freeze Casting: From Low-Dimensional Building Blocks to Aligned Porous Structures-A Review of Novel Materials, Methods, and Applications. Adv. Mater. 2020, 32, No. 1907176.

(35) Deville, S. Freeze-Casting of Porous Ceramics: A Review of Current Achievements and Issues. Adv. Eng. Mater. 2008, 10, 155169.

(36) Shahbazi, M.-A.; Ghalkhani, M.; Maleki, H. Directional FreezeCasting: A Bioinspired Method to Assemble Multifunctional Aligned Porous Structures for Advanced Applications. Adv. Eng. Mater. 2020, 22, No. 2000033.

(37) Zhao, N.; Yang, M.; Zhao, Q.; Gao, W.; Xie, T.; Bai, H. Superstretchable Nacre-Mimetic Graphene/Poly(Vinyl Alcohol) Composite Film Based on Interfacial Architectural Engineering. ACS Nano 2017, 11, 4777-4784.
(38) Yang, M.; Zhao, N.; Cui, Y.; Gao, W.; Zhao, Q.; Gao, C.; Bai, H.; Xie, T. Biomimetic Architectured Graphene Aerogel with Exceptional Strength and Resilience. ACS Nano 2017, 11, 68176824.

(39) Zheng, Z.; Guo, S.; Liu, Y.; Wu, J.; Li, G.; Liu, M.; Wang, X.; Kaplan, D. Lithium-Free Processing of Silk Fibroin. J. Biomater. Appl. 2016, 31, 450-463.

(40) Hummers, W. S.; Offeman, R. E. Preparation of Graphitic Oxide. J. Am. Chem. Soc. 1958, 80, 1339-1339.

(41) Chen, J.; Yao, B.; Li, C.; Shi, G. An Improved Hummers Method for Eco-Friendly Synthesis of Graphene Oxide. Carbon 2013, 64, 225-229.

(42) Alhabeb, M.; Maleski, K.; Anasori, B.; Lelyukh, P.; Clark, L.; Sin, S.; Gogotsi, Y. Guidelines for Synthesis and Processing of TwoDimensional Titanium Carbide $\left(\mathrm{Ti}_{3} \mathrm{C}_{2} \mathrm{~T}_{\mathrm{x}}\right.$ MXene). Chem. Mater. 2017, 29, 7633-7644.

(43) David, G.; Gontard, N.; Guerin, D.; Heux, L.; Lecomte, J.; Molina-Boisseau, S.; Angellier-Coussy, H. Exploring the Potential of Gas-Phase Esterification to Hydrophobize the Surface of Micrometric Cellulose Particles. Eur. Polym. J. 2019, 115, 138-146.

(44) Dianat, G.; Seidel, S.; De Luna, M. M.; Gupta, M. Vapor Phase Fabrication of Hydrophilic and Hydrophobic Asymmetric Polymer Membranes. Macromol. Mater. Eng. 2016, 301, 1037-1043.

(45) Deville, S.; Saiz, E.; Nalla, R. K.; Tomsia, A. P. Freezing as a Path to Build Complex Composites. Science 2006, 311, 515-518.

(46) Gilbert, P. Physics in the Arts, 3rd ed.; Academic Press/Elsevier, 2021.

(47) Asakura, T.; Okushita, K.; Williamson, M. P. Analysis of the Structure of Bombyx mori Silk Fibroin by NMR. Macromolecules 2015, 48, 2345-2357.

(48) Dong, Y.; Wu, Z.-S.; Zheng, S.; Wang, X.; Qin, J.; Wang, S.; Shi, X.; Bao, X. Ti3C2 MXene-Derived Sodium/Potassium Titanate Nanoribbons for High-Performance Sodium/Potassium Ion Batteries with Enhanced Capacities. ACS Nano 2017, 11, 4792-4800.

(49) Wang, X.; Shen, X.; Gao, Y.; Wang, Z.; Yu, R.; Chen, L. Atomic-Scale Recognition of Surface Structure and Intercalation Mechanism of $\mathrm{Ti}_{3} \mathrm{C}_{2}$ X. J. Am. Chem. Soc. 2015, 137, 2715-2721.

(50) Shah, S. A.; Habib, T.; Gao, H.; Gao, P.; Sun, W.; Green, M. J.; Radovic, M. Template-Free 3D Titanium Carbide $\left(\mathrm{Ti}_{3} \mathrm{C}_{2} \mathrm{~T}_{\mathrm{x}}\right)$ MXene Particles Crumpled by Capillary Forces. Chem. Commun. 2017, 53, 400-403.

(51) Sarycheva, A.; Gogotsi, Y. Raman Spectroscopy Analysis of the Structure and Surface Chemistry of $\mathrm{Ti}_{3} \mathrm{C}_{2} \mathrm{~T}_{\mathrm{x}}$ MXene. Chem. Mater. 2020, 32, 3480-3488.

(52) Zhuo, H.; Hu, Y.; Chen, Z.; Peng, X.; Liu, L.; Luo, Q.; Yi, J.; Liu, C.; Zhong, L.; Carbon, A. Aerogel with Super Mechanical and Sensing Performances for Wearable Piezoresistive Sensors. J. Mater. Chem. A 2019, 7, 8092-8100.

(53) Luo, Q.; Zheng, H.; Hu, Y.; Zhuo, H.; Chen, Z.; Peng, X.; Zhong, L. Carbon Nanotube/Chitosan-Based Elastic Carbon Aerogel for Pressure Sensing. Ind. Eng. Chem. Res. 2019, 58, 17768-17775.

(54) Huang, J.; Zeng, J.; Liang, B.; Wu, J.; Li, T.; Li, Q.; Feng, F.; Feng, Q.; Rood, M. J.; Yan, Z. Multi-Arch-Structured All-Carbon Aerogels with Superelasticity and High Fatigue Resistance as Wearable Sensors. ACS Appl. Mater. Interfaces 2020, 12, 1682216830.

(55) Ali, A.; Khan, A.; Karimov, Kh. S.; Ali, A.; Daud Khan, A. Pressure Sensitive Sensors Based on Carbon Nanotubes, Graphene, and Its Composites. J. Nanomater. 2018, 2018, No. 9592610.

(56) Lin, X.; Zhang, T.; Cao, J.; Wen, H.; Fei, T.; Liu, S.; Wang, R.; Ren, H.; Zhao, H. Flexible Piezoresistive Sensors Based on Conducting Polymer-Coated Fabric Applied to Human Physiological Signals Monitoring. J. Bionic. Eng. 2020, 17, 55-63.

(57) Zhao, S.; Liu, R.; Fei, C.; Zia, A. W.; Jing, L. Flexible Sensor Matrix Film-Based Wearable Plantar Pressure Force Measurement and Analysis System. PLoS One 2020, 15, No. e0237090.

(58) Li, Q.; Luo, S.; Wang, Q.-M. Piezoresistive Thin Film Pressure Sensor Based on Carbon Nanotube-Polyimide Nanocomposites. Sens. Actuator, A 2019, 295, 336-342. 
(59) Gao, L.; Wang, Y.; Hu, X.; Zhou, W.; Cao, K.; Wang, Y.; Wang, W.; Lu, Y. Cellular Carbon-Film-Based Flexible Sensor and Waterproof Supercapacitors. ACS Appl. Mater. Interfaces 2019, 11, $26288-26297$. 